\title{
OXYGEN ISOTOPIC HETEROGENEITY IN THE SOLAR SYSTEM INHERITED FROM THE PROTOSOLAR MOLECULAR CLOUD
}

AlEXANDER N. KROT ${ }^{1}$, KAZUHIDE NAGASHIMA ${ }^{1}$, JAMES R. LYONS ${ }^{2}$, JEONG-EUN LEE ${ }^{3}$, AND MARTIN BIZZARRO ${ }^{4}$

${ }^{1}$ University of Hawai‘i at Mānoa, USA. sasha@hawaii.edu

${ }^{2}$ Arizona State University, USA. jrlyons2@asu.edu

${ }^{3}$ Kyung Hee University, KOREA. jeongeun.lee@khu.ac.kr

${ }^{4}$ University of Copenhagen, Denmark. bizzarro@sund.ku.dk

The Sun is ${ }^{16} \mathrm{O}$-enriched $\left(\Delta^{17} \mathrm{O}=-28.4 \pm 3.6 \%\right.$ ) relative to the terrestrial planets, asteroids and chondrules $\left(-7 \%<<\Delta^{17} \mathrm{O}\right.$ $<3 \%$ ) [1]. Ca,Al-rich inclusions (CAIs) and amoeboid olivine aggregates (AOAs) are the only solids formed in the Solar System (SS) with $\Delta^{17} \mathrm{O}$ approaching the solar value. Ultraviolet $\mathrm{CO}$ self-shielding [2] resulting in formation of ${ }^{16} \mathrm{O}$-rich $\mathrm{CO}$ and ${ }^{17,18} \mathrm{O}$-enriched $\mathrm{H}_{2} \mathrm{O}$ is the currently favored mechanism invoked to explain the observed range of $\Delta{ }^{17} \mathrm{O}$ among extraterrestrial materials [3-5]. However, the location of the CO self-shielding is not known: this process is suggested to have occurred either in the protosolar molecular cloud [2,3] or in the outer protoplanetary disk [4]. In the latter case, the self-shielding effects in $\mathrm{CO}$ and $\mathrm{H}_{2} \mathrm{O}$ are estimated to have been transferred to the inner SS within several hundred thousand years [4]. CAIs are the oldest SS solids dated [5] and are thought to have formed near the protoSun. Here we show that grossite-rich CAIs with the predominantly low $\left(<5 \times 10^{-6}\right)$ initial ${ }^{26} \mathrm{Al} /{ }^{27} \mathrm{Al}$ ratio from $\mathrm{CH} 3.0$ chondrites have uniform $\Delta^{17} \mathrm{O}$, but exhibit a large range of $\Delta^{17} \mathrm{O}$ between individual CAIs ( $-40 \%$ to $-5 \%$ ), providing a strong evidence for large variations in $\Delta^{17} \mathrm{O}$ of the nebular gas in the $\mathrm{CH}$ CAI-forming region. In contrast, CAIs with the canonical initial ${ }^{26} \mathrm{Al} /{ }^{27} \mathrm{Al}$ ratio of $\sim 5 \times 10^{-5}$ from the $\mathrm{CR} 2, \mathrm{CM} 2$, and $\mathrm{CO} 3.0$ chondrites have a very limited range of $\Delta^{17} \mathrm{O},-24 \pm 2 \%$ [7-9]. Because CAIs with the low initial ${ }^{26} \mathrm{Al} /{ }^{27} \mathrm{Al}$ are thought to have predated the canonical CAIs and formed within first 10,000-20,000 years of the SS evolution [10], these observations suggest isotopic heterogeneity of the major O-bearing species $\left(\mathrm{CO}, \mathrm{H}_{2} \mathrm{O}\right.$, and silicates) in the early SS was inherited from the protosolar molecular cloud.

References: [1] McKeegan K. D. et al. (2011) Science 332:1528. [2] Thiemens M. H. \& Heidenreich J. (1983) Science 219:1073. [3] Clayton R. N. (2002) Nature 415:860. [4] Yurimoto H. \& Kuramoto K. (2004) Science 305:1763. [5] Lyons J. R. \& Young E. D. (2005) Nature 435:317. [6] Connelly J. N. et al. (2012) Science 338, 651. [7] Makide K. et al. (2009) GCA 73:5018. [8] Kööp L. et al. (2016) $G C A$ 184:151. [9] Ushikubo T. et al. (2017) GCA 201:103. [10] Pignatale F. C. et al. (2018) ApJL 867:L23. 